\title{
Short- to mid-term outcomes of computer navigation assisted total knee arthroplasty using adjusted mechanical alignment compared to mechanical alignment
}

\author{
Kai Zheng \\ First Affiliated Hospital of Soochow University \\ Houyi Sun \\ First Affiliated Hospital of Soochow University \\ Weicheng Zhang \\ First Affiliated Hospital of Soochow University \\ Feng Zhu \\ First Affiliated Hospital of Soochow University \\ Jun Zhou
}

First Affiliated Hospital of Soochow University

Yaozeng Xu ( $\nabla$ xuyaozeng@163.com)

Department of Orthopedics,The First Affiliated Hospital of Soochow University https://orcid.org/00000002-0424-4884

Research article

Keywords: Navigation, Total knee arthroplasty, Mechanical alignment, Adjusted mechanical alignment, Soft tissue balance

Posted Date: March 23rd, 2021

DOI: https://doi.org/10.21203/rs.3.rs-337246/v1

License: (c) (i) This work is licensed under a Creative Commons Attribution 4.0 International License. Read Full License 


\section{Abstract \\ Purpose}

To evaluate efficacy of navigation-assisted total knee arthroplasty (TKA) achieved using adjusted mechanical alignment (aMA) and mechanical alignment (MA) technique.

\section{Methods}

The authors performed a retrospective study enrolled a single-center series of patients who underwent navigation-assisted TKA with aMA $(n=77)$ and with MA $(n=61)$ technique. The demographic data was recorded. Functional scores including Hospital for Special Surgery score, Western Ontario and McMaster Universities Osteoarthritis Index score and Forgotten Joint Score-12 were evaluated. In addition, the parameter of resection and soft tissue balance as well as radiographic evaluation was measured and compared between groups.

\section{Results}

The HSS score at 1-month and 6-months postoperatively were significant higher using aMA compared to MA. The postoperative coronal alignment was made with a mean of $1.11^{\circ}$ more varus/valgus in the aMA group compared to MA. The femoral prosthesis was positioned in a mean of $2.29^{\circ}$ more varus/valgus using aMA compared to MA. The medial extension gap was significantly tighter in the MA group. In addition, the femoral prosthesis in the aMA group was positioned in a mean of $0.77^{\circ}$ more external rotation than the MA group. The lateral flexion gap was wider in the aMA group with a mean of $0.71 \mathrm{~mm}$ more laxity.

\section{Conclusions}

Both aMA and MA technique in TKA obtained good clinical outcomes. Notably, aMA-TKA grant superior functional scores at 1-month and 6-months follow-up, might due to the preservation of mild constitutional frontal deformity with less release of soft tissue and a biomimetic wider lateral flexion gap was remained.

\section{Introduction}

In recent decades, mechanical alignment (MA) technique, which pursues neutral aligned lower limb and symmetrical rectangular flexion-extension gap, has been considered as the gold standard for total knee arthroplasty (TKA)[1]. In mechanically aligned TKA (MA-TKA), the resection of femur and tibia was referred to neutral axis and soft tissue release techniques, such as pie-crusting and multiple needle puncturing, were frequently performed to make up for insufficient osteotomy and imbalanced flexion- 
extension gap[2, 3]. As we known, MA-TKA leads to successful clinical results with good long-term prosthesis survivorship[4, 5]. However, dissatisfaction after MA-TKA was approximately met one in five patients and high rates of disappointing residual symptoms were observed in spite of continuous evolutions in prosthesis designs or assistance with artificial intelligence devices[6-8].

To improve clinical outcomes and enhance patient satisfaction, multiple TKA alignment techniques have been proposed to challenge the conventional MA-TKA. Alternative alignment philosophies consist of (1) anatomic alignment (AA) [9], characterized by a physiological $2^{\circ}-3^{\circ}$ oblique joint line relative to the mechanical axis; (2) kinematic alignment (KA)[10], characterized by maintained native pre-arthritis limb alignment and knee laxity with a pure bone resection procedure; (3) restricted kinematic alignment (rKA) [11], characterized by adjusted kinematic alignment and joint line obliquity on the tibial side to compromise deformity in a safe zone $\left(\leq 3^{\circ}\right)$; (4) adjusted mechanical alignment (aMA)[12], characterized by a slight constitutional deformity (maximum of $3^{\circ}$ ) preservation and adjustment was made by finetuning the femoral implant positioning. Of these, several studies have investigated the clinical outcomes of TKA between the MA-TKA vs. AA-TKA or MA-TKA vs. KA-TKA[13-16]. However, there was still no studies made comparison between the MA technique and aMA technique to assess the functional results of TKA.

Therefore, for the first time, the aim of the present study was to verify short- to mid-term clinical efficacy of navigation-assisted TKA in patients performed by MA vs. those using aMA technique.

\section{Materials And Methods}

\section{Patients}

From October 2017 to September 2019, 138 TKAs in 115 patients performed using MA or aMA technique were reviewed in accordance with the inclusion and exclusion criteria. The inclusion criteria were patients underwent TKAs for end-stage knee arthritis, including osteoarthritis and rheumatoid arthritis; all operations were performed by one single experienced orthopedic surgeon, who had together performed > 500 conventional TKAs and $>200$ computer-assisted navigation TKAs. Patients were excluded if they had: severe cardiopulmonary diseases; history of previous knee surgery or fracture around the knee; a neuromuscular or neurosensory deficiency with muscle atrophy.

\section{Operative techniques}

All operations were performed using general anesthesia. A medial parapatellar capsular approach through a midline skin incision was used in all knees. All TKAs were performed using a cemented, fixedbearing implant (Columbus UC, B. Braun Aesculap, Germany) with the assistance of OrthoPilot navigation system (version 5.1; B. Braun Aesculap, Germany). Tibial preparation was performed first in all patients, and no patellar resurfacing was performed for all patients. 
The aMA theory is an extension of the conventional MA. Briefly, the purpose of the aMA method used in the present study is to correct the constitutional coronal limb deformity into a safe alignment zone $\left(\leq 3^{\circ}\right.$ varus or valgus) $[17,18]$. Unlike the MA technique, which required to correct alignment to neutral 0-degree axis, the aMA technique allowed to preserve slight to moderate constitutional frontal deformity due to the protection of soft tissue. Only severe coronal limb alignment deviation was adjusted to a maximum of $3^{\circ}$ varus or valgus. In addition, the adjustment of prosthesis positioning was fine-tuned on the femoral side while kept the tibial side aligned as same as the MA[19].

In the aMA group, computer navigation was used to assist surgeon in accurate resection and soft tissue balance. Tibial and femoral transmitters were positioned accordingly to capture the infrared for the step of registration. After the approval of bony anatomical landmarks, the system calculated the mechanical femoral and tibial axis in coronal and sagittal planes automatically[20]. Osteophytes were then removed. Navigation was performed to position the tibial cutting guide perpendicular to the mechanical tibial axis. After that, tibial resection and verification were made with the guidance of computer navigation. Next, alignment on the femur side was adjusted followed the feedback of navigation to meet the balance of flexion-extension gap without ligament releases. The aim of balance in aMA-TKA was not the routinely rectangular gap. In aMA-TKA, the lateral gap laxity was wider than the medial gap and a wider flexion gap laxity was remained. Femur resection was then made in accordance with the cutting plan. Finally, trial prostheses were implanted and a final set of checks, including stability, range of motion and patellar tracking were made before cementation of the definitive prosthesis in situ (Fig. 1).

In the MA group, the basic surgical procedures were the same as described in aMA technique. However, the goal of MA technique was achieving overall neutral mechanical axis with $0^{\circ}$ varus/ valgus coronal limb alignment. Navigation was used to position both tibial and femoral four-in-one cutting block at $90^{\circ}$ to the mechanical axis of each bone. Moreover, the aim of balance in MA-TKA was pursuing a symmetrical rectangular gap. Ligament and soft tissue releases, such as pie-crusting and multiple needles puncturing technique, were commonly performed to achieve a balance of symmetric flexion and extension gap (Fig. 2).

\section{Rehabilitation}

To help patients recover faster and better, the concept of enhanced recovery after surgery (ERAS)[21] was applied. Routine tranexamic acid was administered preoperatively and at 3 hours, 6 hours and 9 hours postoperatively to minimize blood loss. Meanwhile, the drainage tube was pulled out within $48 \mathrm{~h}$ postoperatively. Active motion of the knee with muscle strength exercise was encouraged by physical therapist immediately on the same day postoperatively. Under the guidance of physical therapist, patients started sitting, standing and walking with a walker at least 3 times daily in order to achieve at least 60 meters walking with correct gait before discharged.

\section{Clinical and radiographic evaluation}


Clinical and functional outcomes were evaluated by Hospital for Special Surgery (HSS) score[22], Western Ontario and McMaster Universities Osteoarthritis Index (WOMAC) score[23] and Forgotten Joint Score-12 (FJS-12) [24]. The evaluation was performed preoperatively and at 1, 6, 12 months and last follow-up postoperatively. In addition, the parameter of resection and soft tissue balance was measured, including tibia resection angle, frontal femoral angle, axial femoral angle, medial and lateral gap in extension and flexion position and joint line translation. The standing full-lower limb, anteroposterior and lateral view of radiographs were taken by EOS ${ }^{\circledR}$ biplanar X-ray imaging[25]. All radiographs were stored and reviewed via the Picture Archiving and Communication System (PACS, Neusoft, Shenyang, China). The radiographic evaluation (Fig. 3) consisted of the mechanical axis (a), coronal femoral component angle $(\beta)$, coronal tibial component angle $(\mathrm{\gamma})$, sagittal femoral component angle $(\delta)$, tibial posterior slope angle $(\varepsilon)$, femoral-patella angle (Q) and femoral notching were measured. Assessors and patients were blinded to the alignment technique performed in TKA.

\section{Statistical analysis}

The results were presented as means \pm standard deviation for continuous variables, and frequencies and percentages were calculated for categorical variables. Comparison of continuous variables between groups was conducted using independent sample t-test. Chi-square or Fisher exact test was performed to compare categorical variables. Value of $p<0.05$ was considered to be statistically significantly different.

\section{Results}

\section{Demographic Data}

There were 51 female and 12 male patients with an average age of $68.13 \pm 8.78$ years (range, 46 to 86 ) in the aMA group. In the MA group, there were 46 female and 6 male patients with an average age of $68.30 \pm 6.34$ years (range, 56 to 83 ). The mean body mass index (BMI) was $26.13 \pm 4.07 \mathrm{~kg} / \mathrm{m}^{2}$ and $25.52 \pm 3.52 \mathrm{~kg} / \mathrm{m}^{2}$, respectively in both groups. A minimum follow-up of 18 months was achieved in all patients (mean 31.41 months; range, 18 to 41 months). The baseline data were comparable between the aMA and MA group.

\section{Resection and Soft Tissue Balance}

The tibia resection angle was similar between two groups (Table 1). The femoral prosthesis was positioned in a mean of $2.29^{\circ}$ more varus/valgus in the aMA group $(p<0.001)$. The medial extension gap was significantly tighter in the MA group $(p=0.019)$. In addition, the femoral prosthesis in the aMA group was positioned in a mean of $0.77^{\circ}$ more external rotation than the MA group $(p=0.027)$. The lateral flexion gap was wider in the aMA group with a mean of $0.71 \mathrm{~mm}$ more laxity $(p=0.001)$. Also, the difference of $M-L$ flexion laxity was significantly wider using aMA compared to MA $(p<0.001)$. There was no statistically difference in lateral extension gap, medial flexion gap and joint line translation between two groups. 


\section{Radiographic evaluation}

There was no statistically difference in preoperative coronal lower limb alignment between groups (aMA $169.05 \pm 6.12^{\circ}$ versus MA $170.78 \pm 6.01^{\circ}$, Table 2 ). The postoperative coronal alignment was made with a mean of $1.11^{\circ}$ more varus/valgus in the aMA group $(p<0.001)$. The coronal femoral component angle was larger in the aMA group with a mean of $1.77^{\circ}$ more $(p<0.001$, Fig. 4$)$. No statistically difference in sagittal femoral component angle, tibial component angle in the coronal and sagittal plane, femoralpatella angle and femoral notching were observed between groups.

\section{Clinical evaluation}

The preoperative HSS score, WOMAC score and range of the knee motion were similar between the aMA and MA group. Both aMA-TKA and MA-TKA achieved satisfied clinical function outcome. However, the HSS score at 1 month and 6 months postoperatively were significant higher in the aMA group compared to the MA group $(p<0.001 ; p=0.022$, Fig. 5). There was no statistically difference in HSS score, WOMAC score and FJS-12 score in the other periods of follow-up between groups (Table 3 ).

\section{Complications}

Seven $(9.09 \%)$ patients in the aMA group and six (9.84\%) in the MA group were detected with lower limb deep vein thrombosis (DVT), most of which were intermuscular vein thrombosis beneath the level of knee. All DVT were successfully treated with routine anticoagulant therapy. There was no knee infection, prosthesis loosening, patellofemoral problems, pin site fracture, dislocation neither neurovascular injury happened during the follow-up.

\section{Discussion}

Mechanically aligned (MA) implant positioning has been recommended as a longstanding primary goal in TKA, aiming to establish a systematically biomechanical prosthesis knee with evenly load distribution and patellar stability[26]. MA-TKA generally exhibits successful long-term prosthesis survivorship, however, the functional outcomes of MA-TKA have plateaued regardless of improvements in designs of prosthesis or precision of surgery[7, 8, 27]. In contrast, aMA technique is considered as an extension of the conventional MA technique in TKA, aiming to correct the coronal lower limb deformity within a maximum of $3^{\circ}$ varus or valgus by tuned the position of femoral component, without performed soft tissue releases as much as possible. aMA-TKA was reported to provide good clinical outcomes for varus and valgus knees[28]. However, as far as we are aware, no comparable clinical study between aMA and MA technique in TKA has been previously performed, which is possibly due to the limited choices of alignment technique under conventional instruments. The accuracy of operation is extremely hard to be controlled within $1^{\circ}$ deviation in conventional TKA. As a result, surgeons have no additional choices but to perform MA technique, which is the easiest alignment could be achieved manually. However, the high accuracy and repeatability of computer navigation system makes it possible for surgeons to choose aMA technique consciously. Therefore, for the first time in this retrospectively comparative study, we make a 
comparison between the aMA and MA technique in computer navigation-assisted TKA at a mean of 31.41 months follow-up.

Restoration of neutrally aligned lower limb has been considered as the gold standard for TKA believed by most knee surgeons for decades, aiming to reduce the wear of prothesis by created a biomechanical friendly artificial knee. Ritter et al. indicated that malalignment of the component could increase the risk of implant failure[29]. In addition, the preservation of varus tibial deformity with a BMl of $>33.7 \mathrm{~kg} / \mathrm{m}^{2}$ represented contributors to failure of TKA[5]. Comparable results are highlighted in the other publications[30, 31]. However, some new views have been proposed by other scholars. Distinct population have different proportions of physiological varus knees. Bellemans et al. reported that $32 \%$ male and $17 \%$ female existed constitutional varus knees with a mechanical coronal alignment more than $3^{\circ}$ varus in European population[26]. The clinical outcomes may not be satisfied and desirable in these cases if restored the alignment to neutral. This step might lead to under-resection of the distal lateral femoral condyle, and therefore caused patellofemoral problems and altered tightness in deep flexion[32]. Moreover, patients with slight undercorrection following TKA even lead to better functional outcomes in varus knees with a mean of 7.2 years follow-up[12]. In our study, we found similar tibial resection angle in the aMA and MA groups. However, the overall coronal limb alignment averaged $1.11^{\circ}$ more varus/valgus and femoral component was placed in $2.29^{\circ}$ more varus/valgus in the aMA group, which is consistent with the findings of Winnock et al., who adjusted femoral component to preserve mild constitutional deformity with the aMA technique[28]. These findings also match the stated concept of kinematic alignment technique to reverse the alignment of the pre-arthritis native knee[33]. In addition, the fault tolerance of the artificial joint prosthesis increased following the modification of prosthetic design and materials. Therefore, aMA might be suggested as a more rational target to treat patients with constitutional knee deformity. This aligned technique aims to preserve mild varus for varus knees and some valgus for valgus knees, due to avoid extensive and multiple soft tissue releases.

The classical symmetrical rectangular flexion and extension gap is typically thought to be one of the prerequisites for successful TKA. Imbalanced soft tissue may be the risk factor for patellofemoral problems, instability and failure of TKA[34, 35]. In MA-TKA, the resection of tibia and femur was perpendicular to the mechanical axis of each bone. As a result, an imbalanced trapezoidal gap was frequently produced. To purse the balanced flexion and extension gap, multiple additional bony resection and soft tissue release techniques are needed, such as pie-crusting and multiple needle puncturing techniques. However, repeat multiple bone resection or soft tissue and ligament releases may create more imbalance. Studies on the cadaveric knee has showed that the flexion gap is typically larger than the extension gap, meanwhile, the lateral flexion laxity tends to be wider than the medial flexion laxity if the anterior and posterior cruciate ligaments are intact[36]. Moreover, physiological human knee is characterized by the medial-pivot motion with a much more stable medial compartment[37]. In our study, we obtained a satisfied balance of flexion-extension gap by adjusted the position of femoral component without performing soft tissue releases in the aMA group, which meet the view of Howell et al., who advocated restoration of native knee alignment to avoid unnecessary releases of lateral ligaments. In the 
aMA group, the lateral gap laxity was wider than the medial gap and a wider flexion gap laxity was produced, which is consistent with the findings reported by Yoo et al in normal knee joint[38]. In addition, the lateral flexion gap was significantly wider in the aMA group with a mean of $0.71 \mathrm{~mm}$ more laxity than the MA group, which matches the results of McEwen et al, who revealed a wider lateral flexion gap laxity $(>2 \mathrm{~mm})$ was associated with better clinical and functional outcomes[39].

The clinical and functional outcomes of both the aMA and MA technique in this study were satisfied. However, we found the HSS score at 1 month and 6 months postoperatively were significant higher in the aMA group compared to the MA group. No statistically difference in HSS score, WOMAC score and FJS12 score was observed in the other periods of follow-up between groups. Preservation of mild constitutional frontal deformity with less release of soft tissue, also a biomimetic asymmetric flexionextension gap, may be the causes of the superior functional scores in the aMA group. After six months, the healing of soft tissue and ligaments tends to make the function of knee equivalent in both groups.

There were no statistically difference in the rate of complications between the aMA and MA group. Boldt et al. reported that the increased rotation and varus/valgus of the femoral component is possibly correlation with adversely effect on patellofemoral tracking[40]. However, no increase in the incidence of patellofemoral problems was observed in the aMA group, which is similar to the previous studies performed with kinematic alignment technique in TKA.

There are several limitations of the current study should be mentioned. First, this was a retrospective control study which may increase the selection bias and recall bias. A prospective randomized controlled trial was needed to further investigate the outcomes between the aMA and MA technique. Second, the sample size was relatively small and the mean period of follow-up was only 31.41 months, which is inadequate to systematically evaluate the complications affected by the alignment technique. Outcomes with a larger size sample and longer-term follow-up are still to be confirmed. Finally, this was a single center research performed by one experienced surgeon, maybe further multicenter clinical studies are required to assess our findings.

\section{Conclusions}

Comprehensively, our study suggested that both aMA and MA technique in TKA obtained good clinical outcomes. Notably, aMA-TKA grant superior functional scores at 1-month and 6-months follow-up, may be due to the preservation of mild constitutional frontal deformity with less release of soft tissue, also a biomimetic wider lateral flexion gap.

\section{Declarations}

Acknowledgements Not applicable.

Funding This work is supported by grants from the National Natural Science Foundation of China (Nos. 82072498, 81672238 and 81873990). 
Conflict of interest The authors have no conflicts of interest to declare that are relevant to the content of this article.

\section{Availability of data and materials}

All data generated or analyzed during this study are included in this published article.

Authors' contributions KZ: study design, data collection, manuscript writing, HYS: data collection, manuscript editing, WCZ: statistical analysis, manuscript editing, FZ: data analysis, JZ: manuscript revision. YZX: patients' treatments and final approvement of submission. All authors read and approved the manuscript.

Ethics approval Ethical approval was waived by the local Ethics Committee of the First Affiliated Hospital of Soochow University in view of the retrospective nature of the study and all the procedures being performed were part of the routine care.

Consent for publication Written informed consent was obtained from the patients for publication of related clinical data and images.

\section{References}

1. Riviere C, Iranpour F, Auvinet E, Howell S, Vendittoli PA, Cobb J, Parratte S (2017) Alignment options for total knee arthroplasty: A systematic review. Orthop Traumatol Surg Res 103:1047-1056. https://doi.org/10.1016/j.otsr.2017.07.010

2. Ha CW, Park YB, Lee CH, Awe SI, Park YG (2016) Selective Medial Release Technique Using the PieCrusting Method for Medial Tightness During Primary Total Knee Arthroplasty. J Arthroplasty 31:1005-1010. https://doi.org/10.1016/j.arth.2015.11.019

3. Siong FT, Kim TW, Kim SC, Lee ES, Jaffar MSA, Lee YS (2020) Efficacy and Safety of Functional Medial Ligament Balancing With Stepwise Multiple Needle Puncturing in Varus Total Knee Arthroplasty. J Arthroplasty 35:380-387. https://doi.org/10.1016/j.arth.2019.09.005

4. Patil S, McCauley JC, Pulido P, Colwell CW, Jr. (2015) How do knee implants perform past the second decade? Nineteen- to 25-year followup of the Press-fit Condylar design TKA. Clin Orthop Relat Res 473:135-140. https://doi.org/10.1007/s11999-014-3792-6

5. Berend ME, Ritter MA, Meding JB, Faris PM, Keating EM, Redelman R, Faris GW, Davis KE (2004) Tibial component failure mechanisms in total knee arthroplasty. Clin Orthop Relat Res:26-34. https://doi.org/10.1097/01.blo.0000148578.22729.0e

6. Bourne RB, Chesworth BM, Davis AM, Mahomed NN, Charron KD (2010) Patient satisfaction after total knee arthroplasty: who is satisfied and who is not? Clin Orthop Relat Res 468:57-63. https://doi.org/10.1007/s11999-009-1119-9

7. Nam D, Nunley RM, Barrack RL (2014) Patient dissatisfaction following total knee replacement: a growing concern? Bone Joint J 96-B:96-100. https://doi.org/10.1302/0301-620X.96B11.34152 
8. Abdel MP, Parratte S, Blanc G, Ollivier M, Pomero V, Viehweger E, Argenson JN (2014) No benefit of patient-specific instrumentation in TKA on functional and gait outcomes: a randomized clinical trial. Clin Orthop Relat Res 472:2468-2476. https://doi.org/10.1007/s11999-014-3544-7

9. Hungerford DS, Kenna RV, Krackow KA (1982) The porous-coated anatomic total knee. Orthop Clin North Am 13:103-122.

10. Lee YS, Howell SM, Won YY, Lee OS, Lee SH, Vahedi H, Teo SH (2017) Kinematic alignment is a possible alternative to mechanical alignment in total knee arthroplasty. Knee Surg Sports Traumatol Arthrosc 25:3467-3479. https://doi.org/10.1007/s00167-017-4558-y

11. Almaawi AM, Hutt JRB, Masse V, Lavigne M, Vendittoli PA (2017) The Impact of Mechanical and Restricted Kinematic Alignment on Knee Anatomy in Total Knee Arthroplasty. J Arthroplasty 32:21332140. https://doi.org/10.1016/j.arth.2017.02.028

12. Vanlommel L, Vanlommel J, Claes S, Bellemans J (2013) Slight undercorrection following total knee arthroplasty results in superior clinical outcomes in varus knees. Knee Surg Sports Traumatol Arthrosc 21:2325-2330. https://doi.org/10.1007/s00167-013-2481-4

13. Yim JH, Song EK, Khan MS, Sun ZH, Seon JK (2013) A comparison of classical and anatomical total knee alignment methods in robotic total knee arthroplasty: classical and anatomical knee alignment methods in TKA. J Arthroplasty 28:932-937. https://doi.org/10.1016/j.arth.2013.01.013

14. Dossett HG, Estrada NA, Swartz GJ, LeFevre GW, Kwasman BG (2014) A randomised controlled trial of kinematically and mechanically aligned total knee replacements: two-year clinical results. Bone Joint J 96-B:907-913. https://doi.org/10.1302/0301-620X.96B7.32812

15. Young SW, Walker ML, Bayan A, Briant-Evans T, Pavlou P, Farrington B (2017) The Chitranjan S. Ranawat Award: No Difference in 2-year Functional Outcomes Using Kinematic versus Mechanical Alignment in TKA: A Randomized Controlled Clinical Trial. Clin Orthop Relat Res 475:9-20. https://doi.org/10.1007/s11999-016-4844-x

16. Waterson HB, Clement ND, Eyres KS, Mandalia VI, Toms AD (2016) The early outcome of kinematic versus mechanical alignment in total knee arthroplasty: a prospective randomised control trial. Bone Joint J 98-B:1360-1368. https://doi.org/10.1302/0301-620X.98B10.36862

17. De Muylder J, Victor J, Cornu O, Kaminski L, Thienpont E (2015) Total knee arthroplasty in patients with substantial deformities using primary knee components. Knee Surg Sports Traumatol Arthrosc 23:3653-3659. https://doi.org/10.1007/s00167-014-3269-x

18. Deep K, Eachempati KK, Apsingi S (2015) The dynamic nature of alignment and variations in normal knees. Bone Joint J 97-B:498-502. https://doi.org/10.1302/0301-620X.97B4.33740

19. Ranawat AS, Ranawat CS, Elkus M, Rasquinha VJ, Rossi R, Babhulkar S (2005) Total knee arthroplasty for severe valgus deformity. J Bone Joint Surg Am 87 Suppl 1:271-284. https://doi.org/10.2106/JBJS.E.00308

20. Ritter MA, Faris PM, Keating EM, Meding JB (1994) Postoperative alignment of total knee replacement. Its effect on survival. Clin Orthop Relat Res:153-156. 
21. Kehlet H, Wilmore DW (2002) Multimodal strategies to improve surgical outcome. Am J Surg 183:630-641. https://doi.org/10.1016/s0002-9610(02)00866-8

22. Slupik A, Bialoszewski D (2009) A comparative analysis of the clinical utility of the Staffelstein-score and the hospital for special surgery knee score (HSS) in monitoring physiotherapy of total knee replacement patients-preliminary study. Ortop Traumatol Rehabil 11:37-45.

23. Bellamy N, Buchanan WW, Goldsmith CH, Campbell J, Stitt LW (1988) Validation study of WOMAC: a health status instrument for measuring clinically important patient relevant outcomes to antirheumatic drug therapy in patients with osteoarthritis of the hip or knee. J Rheumatol 15:18331840.

24. Cao S, Liu N, Han W, Zi Y, Peng F, Li L, Fu Q, Chen Y, Zheng W, Qian Q (2017) Simplified Chinese version of the Forgotten Joint Score (FJS) for patients who underwent joint arthroplasty: crosscultural adaptation and validation. J Orthop Surg Res 12:6. https://doi.org/10.1186/s13018-0160508-5

25. Melhem E, Assi A, El Rachkidi R, Ghanem I (2016) EOS((R)) biplanar X-ray imaging: concept, developments, benefits, and limitations. J Child Orthop 10:1-14. https://doi.org/10.1007/s11832-0160713-0

26. Bellemans J, Colyn W, Vandenneucker H, Victor J (2012) The Chitranjan Ranawat award: is neutral mechanical alignment normal for all patients? The concept of constitutional varus. Clin Orthop Relat Res 470:45-53. https://doi.org/10.1007/s11999-011-1936-5

27. Fang DM, Ritter MA, Davis KE (2009) Coronal alignment in total knee arthroplasty: just how important is it? J Arthroplasty 24:39-43. https://doi.org/10.1016/j.arth.2009.04.034

28. Winnock de Grave P, Luyckx T, Claeys K, Tampere T, Kellens J, Muller J, Gunst P (2020) Higher satisfaction after total knee arthroplasty using restricted inverse kinematic alignment compared to adjusted mechanical alignment. Knee Surg Sports Traumatol Arthrosc. https://doi.org/10.1007/s00167-020-06165-4

29. Ritter MA, Davis KE, Meding JB, Pierson JL, Berend ME, Malinzak RA (2011) The effect of alignment and BMI on failure of total knee replacement. J Bone Joint Surg Am 93:1588-1596. https://doi.org/10.2106/JBJS.J.00772

30. Innocenti B, Bellemans J, Catani F (2016) Deviations From Optimal Alignment in TKA: Is There a Biomechanical Difference Between Femoral or Tibial Component Alignment? J Arthroplasty 31:295301. https://doi.org/10.1016/j.arth.2015.07.038

31. Slevin O, Hirschmann A, Schiapparelli FF, Amsler F, Huegli RW, Hirschmann MT (2018) Neutral alignment leads to higher knee society scores after total knee arthroplasty in preoperatively nonvarus patients: a prospective clinical study using 3D-CT. Knee Surg Sports Traumatol Arthrosc 26:1602-1609. https://doi.org/10.1007/s00167-017-4744-y

32. Coughlin KM, Incavo SJ, Churchill DL, Beynnon BD (2003) Tibial axis and patellar position relative to the femoral epicondylar axis during squatting. J Arthroplasty 18:1048-1055. https://doi.org/10.1016/s0883-5403(03)00449-2 
33. Howell SM, Howell SJ, Kuznik KT, Cohen J, Hull ML (2013) Does a kinematically aligned total knee arthroplasty restore function without failure regardless of alignment category? Clin Orthop Relat Res 471:1000-1007. https://doi.org/10.1007/s11999-012-2613-z

34. Fehring TK (2000) Rotational malalignment of the femoral component in total knee arthroplasty. Clin Orthop Relat Res:72-79. https://doi.org/10.1097/00003086-200011000-00010

35. Romero J, Stahelin T, Binkert C, Pfirrmann C, Hodler J, Kessler O (2007) The clinical consequences of flexion gap asymmetry in total knee arthroplasty. J Arthroplasty 22:235-240. https://doi.org/10.1016/j.arth.2006.04.024

36. Nowakowski AM, Majewski M, Muller-Gerbl M, Valderrabano V (2012) Measurement of knee joint gaps without bone resection: "physiologic" extension and flexion gaps in total knee arthroplasty are asymmetric and unequal and anterior and posterior cruciate ligament resections produce different gap changes. J Orthop Res 30:522-527. https://doi.org/10.1002/jor.21564

37. Komistek RD, Dennis DA, Mahfouz M (2003) In vivo fluoroscopic analysis of the normal human knee. Clin Orthop Relat Res:69-81. https://doi.org/10.1097/01.blo.0000062384.79828.3b

38. Yoo JC, Ahn JH, Sung KS, Wang JH, Lee SH, Bae SW, Ahn YJ (2006) Measurement and comparison of the difference in normal medial and lateral knee joint opening. Knee Surg Sports Traumatol Arthrosc 14:1238-1244. https://doi.org/10.1007/s00167-006-0095-9

39. McEwen P, Balendra G, Doma K (2019) Medial and lateral gap laxity differential in computer-assisted kinematic total knee arthroplasty. Bone Joint J 101-B:331-339. https://doi.org/10.1302/0301620X.101B3.BJJ-2018-0544.R1

40. Boldt JG, Stiehl JB, Hodler J, Zanetti M, Munzinger U (2006) Femoral component rotation and arthrofibrosis following mobile-bearing total knee arthroplasty. Int Orthop 30:420-425. https://doi.org/10.1007/s00264-006-0085-z

\section{Tables}

Table 1 Resection and Soft Tissue Balance Data 


\begin{tabular}{|llll|}
\hline Parameters & $\begin{array}{l}\text { aMA Group } \\
(\mathrm{n}=77)\end{array}$ & $\begin{array}{l}\text { MA Group } \\
(\mathrm{n}=61)\end{array}$ & $p$ value \\
\hline Tibia resection $\left(^{\circ}\right)$ & $0.42 \pm 0.52$ & $0.33 \pm 0.57$ & 0.348 \\
\hline Extension & & & \\
\hline Frontal femoral angle $\left(^{\circ}\right)$ & $2.55 \pm 1.08$ & $0.26 \pm 0.60$ & $<0.001$ \\
\hline Medial gap $(\mathrm{mm})$ & $0.01 \pm 0.77^{\$}$ & $-0.44 \pm 1.44^{*}$ & 0.019 \\
\hline Lateral gap $(\mathrm{mm})$ & $0.68 \pm 0.94$ & $0.48 \pm 1.67$ & 0.376 \\
\hline Difference of M-L extension laxity $(\mathrm{mm})$ & $0.66 \pm 1.06$ & $0.92 \pm 2.10$ & 0.354 \\
\hline Flexion & & & \\
\hline Axial femoral angle $\left(^{\circ}\right)$ & $3.07 \pm 2.23$ & $2.30 \pm 1.70$ & 0.027 \\
\hline Medial gap (mm) & $0.13 \pm 0.83$ & $0.15 \pm 1.28$ & 0.922 \\
\hline Lateral gap $(\mathrm{mm})$ & $0.92 \pm 0.87$ & $0.21 \pm 1.50$ & 0.001 \\
\hline Difference of M-L flexion laxity $(\mathrm{mm})$ & $0.79 \pm 1.04$ & $0.07 \pm 0.79$ & $<0.001$ \\
\hline Joint line translation (mm) & $1.35 \pm 1.60^{\#}$ & $1.34 \pm 1.60$ & 0.981 \\
\hline
\end{tabular}

M-L medial-lateral; \$positive signifies laxity of the soft tissue; *-negative signifies distension of the soft tissue; " positive signifies proximal translation

Table 2 Radiographic Data 


\begin{tabular}{|c|c|c|c|}
\hline Parameters & $\begin{array}{l}\text { aMA Group } \\
(n=77)\end{array}$ & $\begin{array}{l}\text { MA Group } \\
(n=61)\end{array}$ & $p$ value \\
\hline \multicolumn{4}{|l|}{ Mechanical axis } \\
\hline Preop. $\left({ }^{\circ}\right)$ & $169.05 \pm 6.12$ & $170.78 \pm 6.01$ & 0.098 \\
\hline Deformity of $<10^{\circ}$ & $33(48.05 \%)$ & $31(50.82 \%)$ & \multirow[t]{3}{*}{0.619} \\
\hline Deformity of $10-20^{\circ}$ & $37(48.05 \%)$ & $26(42.62 \%)$ & \\
\hline Deformity of $>20^{\circ}$ & $7(9.09 \%)$ & $4(6.56 \%)$ & \\
\hline Postop. $\left({ }^{\circ}\right)$ & $177.03 \pm 1.82$ & $178.14 \pm 1.69$ & $<0.001$ \\
\hline \multicolumn{4}{|l|}{ Femoral angle } \\
\hline Coronal plane $\left(^{\circ}\right)$ & $92.62 \pm 2.78$ & $90.85 \pm 2.01$ & $<0.001$ \\
\hline Sagittal plane $\left(^{\circ}\right)$ & $2.76 \pm 2.13$ & $2.83 \pm 3.16$ & 0.870 \\
\hline \multicolumn{4}{|l|}{ Tibial angle } \\
\hline Coronal plane $\left(^{\circ}\right)$ & $90.42 \pm 1.47$ & $90.36 \pm 1.17$ & 0.803 \\
\hline Sagittal plane $\left(^{\circ}\right)$ & $90.12 \pm 1.57$ & $89.97 \pm 1.47$ & 0.577 \\
\hline Femoral-patella angle $\left(^{\circ}\right)$ & $30.37 \pm 1.81$ & $29.72 \pm 2.46$ & 0.077 \\
\hline Femoral Notching & $6(7.79 \%)$ & $5(8.20 \%)$ & 0.931 \\
\hline
\end{tabular}

Table 3 Clinical Data 


\begin{tabular}{|llll|}
\hline Parameters & $\begin{array}{l}\text { aMA Group } \\
(\mathrm{n}=77)\end{array}$ & $\begin{array}{l}\text { MA Group } \\
(\mathrm{n}=61)\end{array}$ & $p$ value \\
\hline Preop. & & & \\
\hline Range of motion ( $\left.{ }^{\circ}\right)$ & $111.36 \pm 8.98$ & $111.87 \pm 8.90$ & 0.742 \\
\hline HSS score (points) & $47.44 \pm 7.58$ & $48.71 \pm 7.79$ & 0.339 \\
\hline WOMAC score (points) & $66.16 \pm 8.54$ & $65.49 \pm 8.77$ & 0.655 \\
\hline Postop. & & & \\
\hline Range of motion ( $\left.{ }^{\circ}\right)$ & $123.71 \pm 5.68$ & $122.98 \pm 6.07$ & 0.467 \\
\hline 1 month postop. & & & \\
\hline HSS score (points) & $72.16 \pm 3.10$ & $69.28 \pm 2.51$ & $<0.001$ \\
\hline WOMAC score (points) & $24.13 \pm 1.81$ & $24.34 \pm 2.00$ & 0.510 \\
\hline 6 months postop. & & & \\
\hline HSS score (points) & $85.83 \pm 3.54$ & $84.56 \pm 2.90$ & 0.022 \\
\hline WOMAC score (points) & $17.18 \pm 1.36$ & $17.56 \pm 2.24$ & 0.226 \\
\hline FJS-12 score (points) & $14.29 \pm 3.34$ & $13.73 \pm 5.57$ & 0.468 \\
\hline 1 year postop. & & & 0.919 \\
\hline HSS score (points) & $91.88 \pm 1.37$ & $91.98 \pm 2.30$ & 0.788 \\
\hline WOMAC score (points) & $15.05 \pm 1.73$ & $14.79 \pm 1.88$ & 0.391 \\
\hline FJS-12 score (points) & $25.16 \pm 3.98$ & $25.25 \pm 5.60$ & 0.919 \\
\hline Last follow-up & & & 0.605 \\
\hline HSS score (points) & $94.86 \pm 1.97$ & $94.25 \pm 2.66$ & 0.123 \\
\hline WOMAC score (points) & $12.82 \pm 2.10$ & $12.62 \pm 2.32$ & 0.605 \\
\hline FJS-12 score (points) & $41.59 \pm 4.93$ & $42.09 \pm 8.28$ & 0.661 \\
\hline
\end{tabular}

HSS Hospital for Special Surgery; WOMAC Western Ontario and McMaster Universities Osteoarthritis Index; FJS-12 Forgotten Joint Score-12.

\section{Figures}




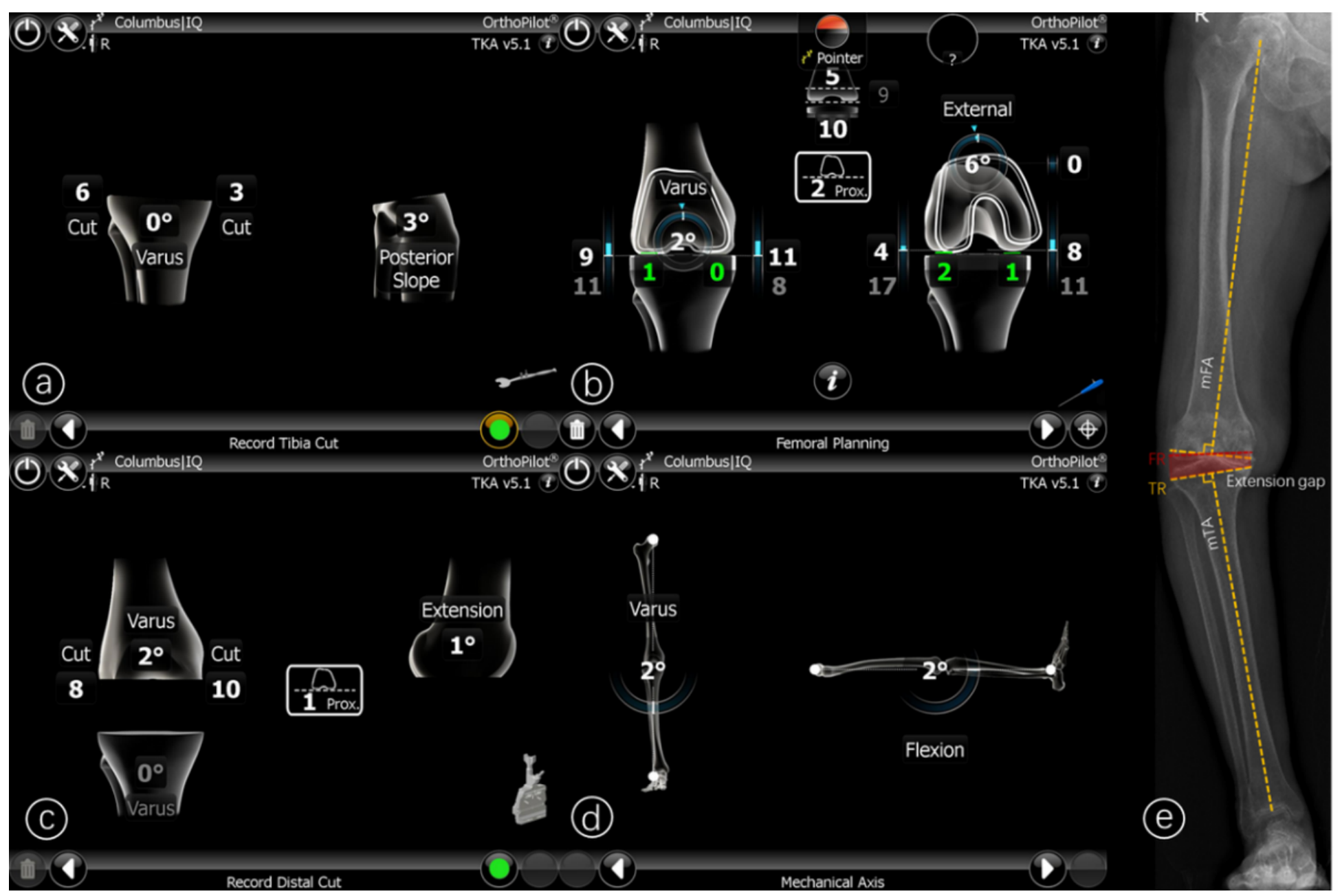

\section{Figure 1}

Operation using the aMA technique assisted by navigation system. a Tibia resection was perpendicular to the mechanical axis of the tibia. b A slight varus deformity was preserved on the femoral side with a biomimetic wider lateral flexion gap. c Record after resection of tibia and femur. $d$ Final coronal alignment after cementation of the definitive prosthesis. e Illustration of aMA in a varus knee. Femoral resection (red) was more varus using aMA compared to MA (orange). Abbreviations: mFA mechanical femoral axis; mTA mechanical tibial axis; FR femoral resection; TR tibial resection. 


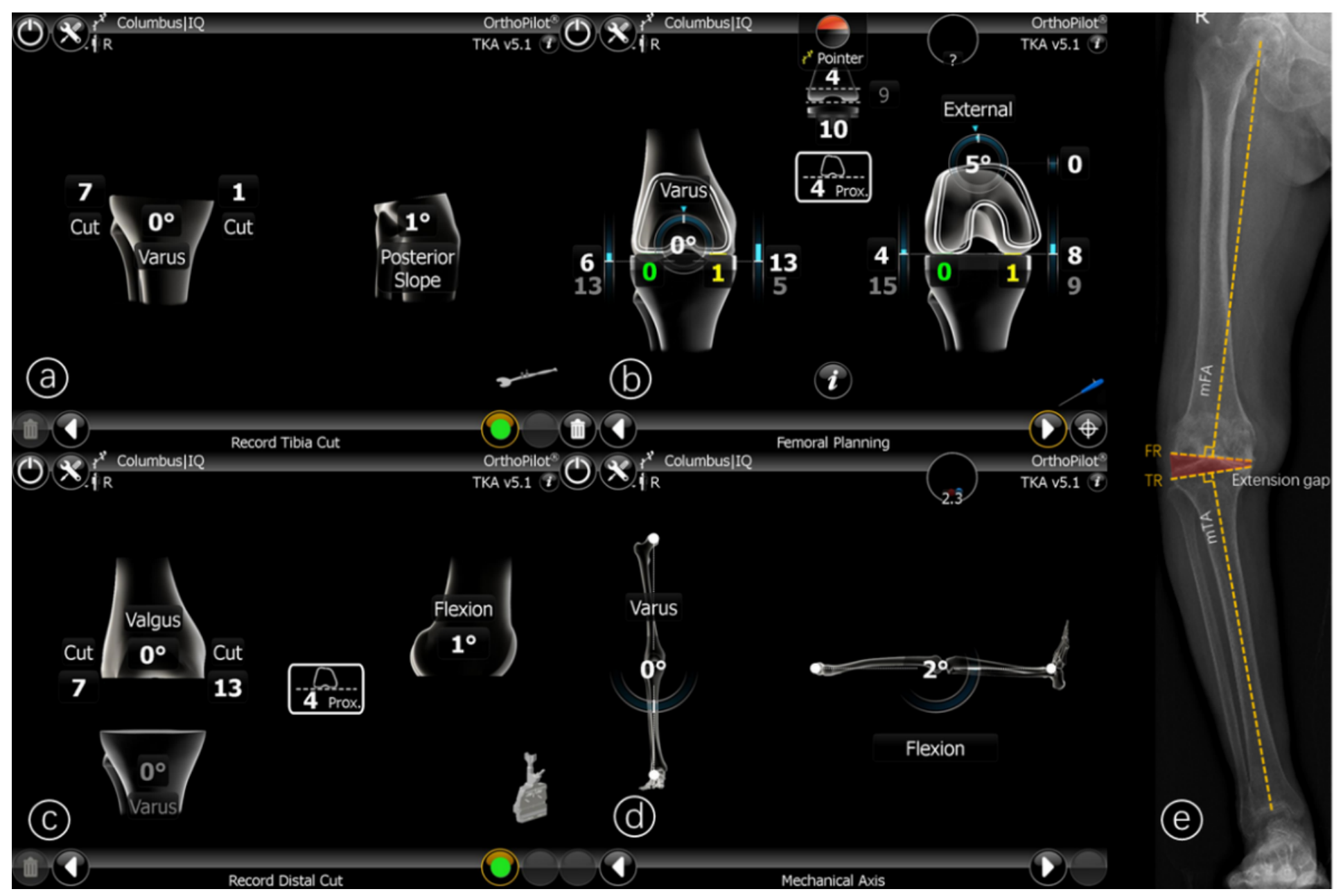

Figure 2

Operation using the MA technique assisted by navigation system. a Tibia resection was at $90^{\circ}$ to the mechanical axis of the tibia. $b$ Femoral resection was perpendicular to the mechanical axis of the femur. $c$ Record after resection of tibia and femur. $d$ Final coronal alignment after cementation of the definitive prosthesis. e lllustration of MA in a common knee described in aMA. An extreme asymmetrical trapezoidal gap was typical produced and soft tissue releases were frequently performed to restore the balance of flexion-extension gap. 


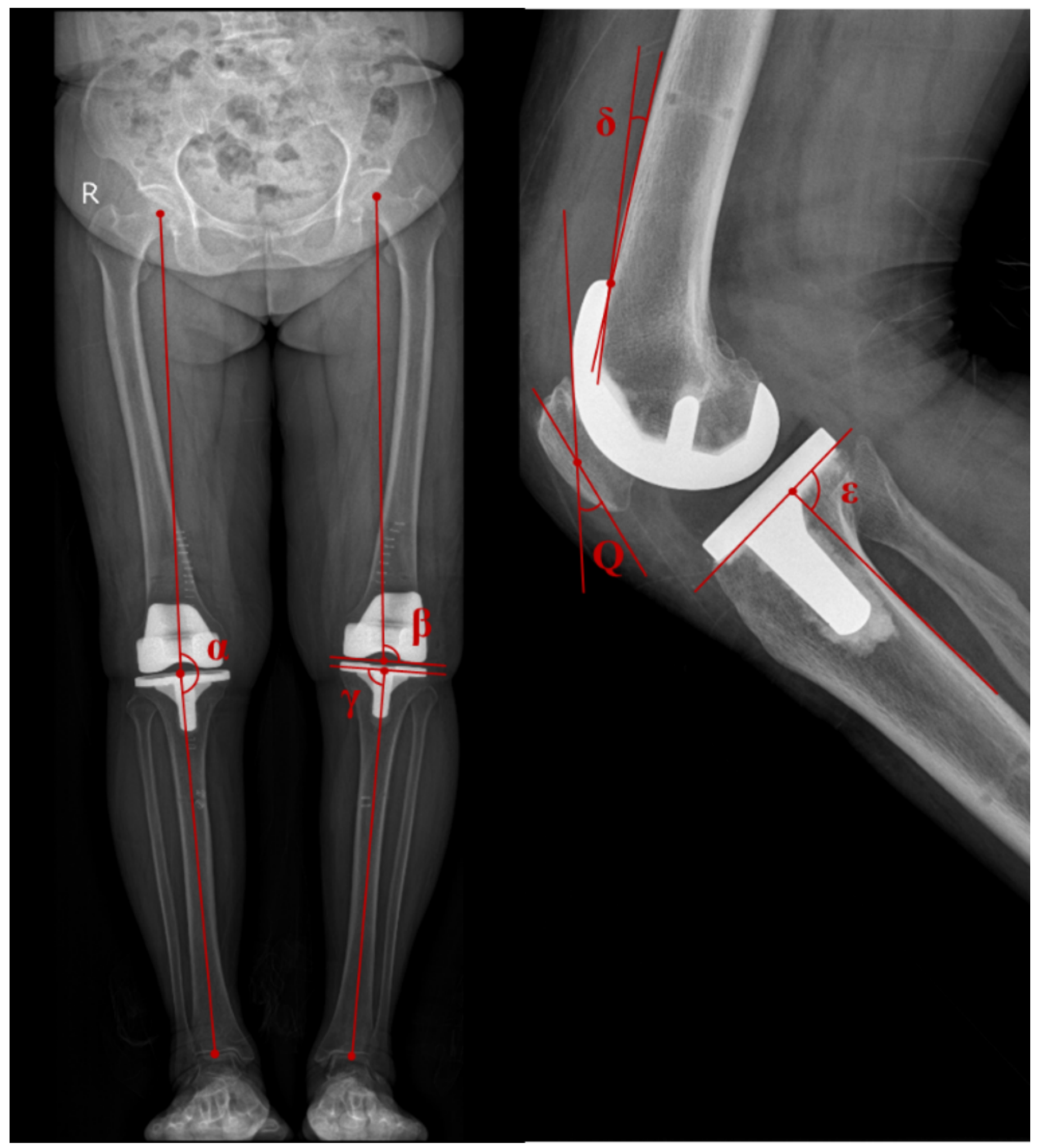

\section{Figure 3}

Illustration of radiographic evaluation. The mechanical axis (a) is the connecting line among the center of the femoral head, knee and ankle; the coronal femoral component angle $(\beta)$ is measured as the angle between the line from the femoral head center to the center of the distal femur and a line parallel to the femoral condyles; the coronal tibial component angle $(\mathrm{Y})$ is measured as the angle between the line from the center of ankle to the center of the proximal tibia and a line along the plateau of tibial component; the 
sagittal femoral component angle ( $\delta)$ is measured as the angle between the frontal femoral cortex and the inner frontal part of the femoral component; the tibial posterior slope angle $(\varepsilon)$ is measured as the angle between the posterior tibial cortex and the plateau of the tibial component; the femoral-patella angle $(\mathrm{Q})$ is measured as the angle between the tangent of anterior femoral component and the anatomical axis of patella.

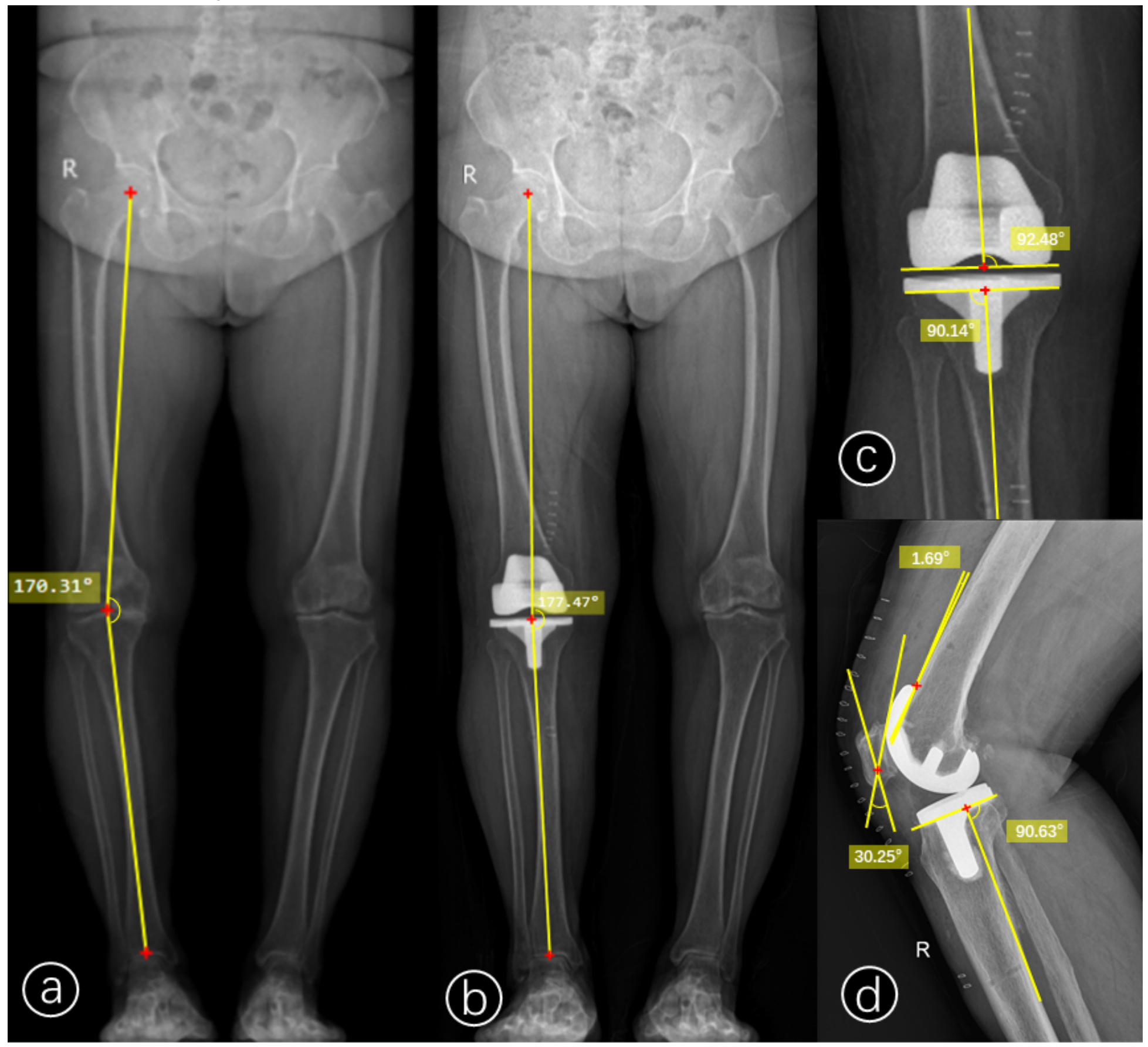

\section{Figure 4}

Radiographs of a 64 years female patient who underwent navigation-assisted TKA using aMA technique. a Preoperative standing full-leg $X$ ray (EOS) showed an osteoarthritis right knee with $170.31^{\circ}$ varus deformity. b Postoperative EOS showed a restored knee with angle of $2.53^{\circ}$ varus left. c Postoperative $X$ 
ray showed a coronal femoral component angle $(\beta)$ of $92.48^{\circ}$ with a corocal tibial component angle $(\gamma)$ of $90.14^{\circ}$. d Postoperative $X$ ray showed a sagittal femoral component angle $(\delta)$ of $1.69^{\circ}$, tibial posterior slope angle $(\varepsilon)$ of $90.63^{\circ}$ and femoral-patella angle (Q) of $30.25^{\circ}$.

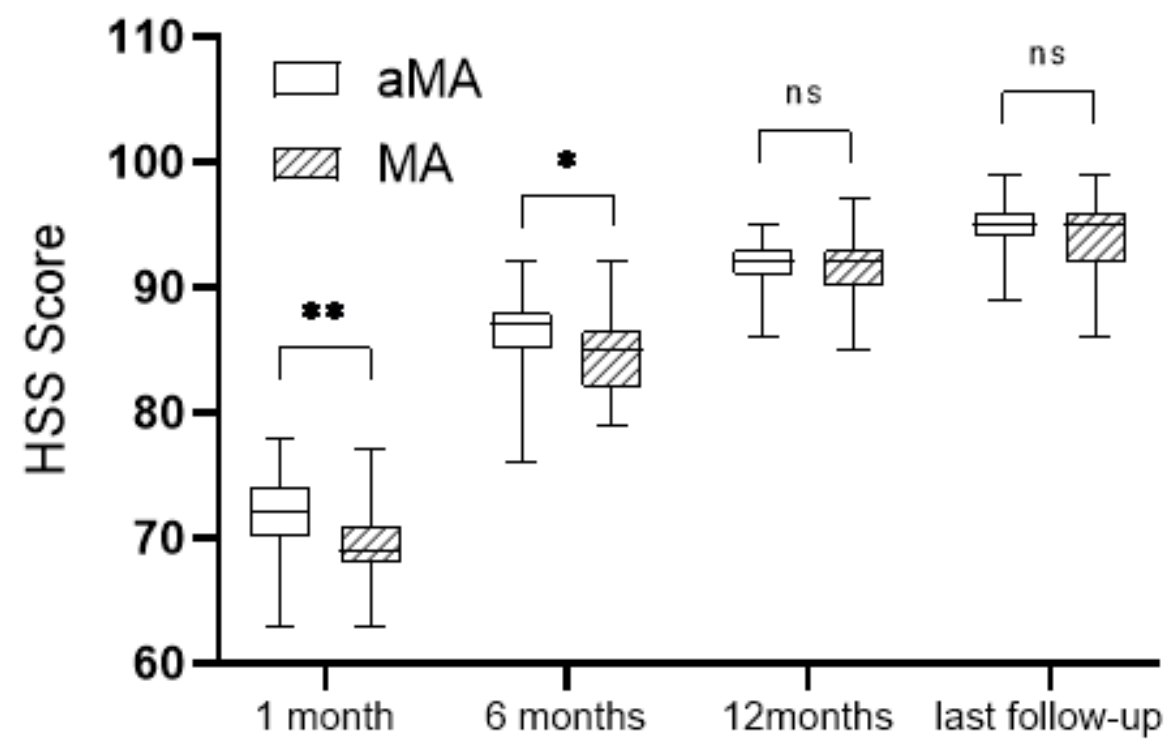

Figure 5

Comparative box plot of HSS score showed that HSS score at 1 month and 6 months postoperatively were significant higher in the aMA group compared with the MA group. 